\title{
Lack of Association of the Ghrelin Gene Arg51Gln Single Nucleotide Polymorphism with Obesity and Metabolic Syndrome among Multi-ethnic Malaysian Subjects
}

\author{
Sher-Wyn Lui ${ }^{1}$, Phee-Phee Chia ${ }^{2}$, Yee-How Say ${ }^{1, *}$ \\ ${ }^{1}$ Department of Biomedical Science, Faculty of Science \\ ${ }^{2}$ Department of Science and En gineering, Centre for Foundation Studies Universiti Tunku Abdul Rahman (UTAR) Perak Campus, 31900 \\ Kampar, Perak, Malaysia
}

\begin{abstract}
Obesity and metabolic syndrome has become a public health concern because of its association with a number of medical complications that lead to increased morbidity and mortality. Ghrelin is a hormone that is primarily secreted in the stomach, which plays an important role to increase hunger through its action on hypothalamic feeding. The Ghrelin gene Arg51Gln single nucleotide poly morphism (SNP) (rs34911341) has been associated with obesity and metabolic syndrome in previous studies. Therefore, this study was to examine the prevalence of this SNP and its association with obesity, obesity-related traits and metabolic syndrome among 184 multi-ethnic Malaysian subjects (67 males, 117 females; 76 obese, 108 non obese; 52 Malay, 91 ethnic Chinese, 41 ethnic Indians) from the Kampar Health Clinic cohort. Demographic data, anthropometric and clinical measurements of subjects were collected. Genotyping was performed by using the genomic DNA extracted from leukocytes, followed by Poly merase Chain Reaction and SacI Restriction Frag ment Length Poly morphism, revealing $113 \mathrm{GG}, 70 \mathrm{GA}$ and $1 \mathrm{AA}$ subjects; minor alle le frequency 0.196 . Arg 51Gln alle les did not show any as sociation with obesity $(p=0.643)$, gender $(p=0.064)$ and ethnicity $(p=0.390)$. Besides, it $\mathrm{did}$ not show any association with the presence of metabolic syndrome according to 3 criteria in the modified NCEP ATP III for Asians $(p=0.931)$. Anthropometric and clinical measurements indicative of obesity and metabolic syndrome were also all not significantly different between the alleles. In conclusion, the Ghrelin Arg51Gln gene variant was not associated with obesity, obesity-related traits and metabolic syndrome among Malaysian subjects in this study.
\end{abstract}

Keywords Ghrelin, Single Nucleotide Polymorphism, Obesity, Metabolic Syndrome, Anthropometric Measurements, Malaysia

\section{Introduction}

Obesity is a medical condition in which excess body fat has accumulated to the extent that it may have an adverse effect on health, leading to reduced life expectancy and increased health problems. It is a multifactorial disease caused by an interaction of genetic factors with lifestyle and environmental factors, and is rapidly increasing world wide[1]. The 2006 Third Malaysian National Health and Morbidity Survey (NHMS III) found that the prevalence of overweight had increased to $29.1 \%$ and that of obese $14.0 \%$; co mpared to the 1996 NHMS II at $16.6 \%$ and $4.0 \%$, respectively[2]. Obesity is a public health concern because its increased prevalence has been accompanied by a parallel increase in the prevalence of the metabolic syndrome (MetS)

* Corresponding author:

sayyh@utar.edu.my (Yee-How Say)

Published online at http://journal.sapub.org/diabetes

Copyright (C) 2012 Scientific \& Academic Publishing. All Rights Reserved or "syndrome X" [3]. Metabolic syndrome is a heterogeneous disorder which is characterized by the presence of three or more of the criteria which include abdominal obesity, elevated triglyceride concentrations, low high-density lipoprotein (HDL) cholesterol, high blood pressure, and elevated fasting glucose[3].

Ghrelin is a synthesized as pre-pro-hormone, then proteolytically processed to yield a 28 a mino acid peptide[4]. The human ghrelin gene (Ghrelin) is located on chromosome 3 , at locus 3p25-26, and consists of 4 exons and 3 introns [5]. Ghrelin is primarily produced in the stomach, as well as by other tissues like intestines, pancreas, hypothalamus, placenta, kidney, gonads and pituitary gland[4]. Ghrelin is the first natural hormone to be identified in which the hydroxyl group of one of its serine residues is acylated with an n-octanoyl[4]. Acylated ghrelin was discovered as the endogenous ligand of the growth hormone secretagogue receptor type 1a (GHSR1a), which stimulates growth hormone release and regulates appetite[6]. Ghrelin circulates in the bloodstream and shows pulsatile secretion, with levels 
higher on fasting and lower levels after food intake[6]. It modulates gastric motility and acid secretion, inhibits gastric emptying, and affects insulin and gastrin secretion, indicating that ghrelin has oxiregenic effect coupled with control of energy expenditure, gastric motility and acid secretion[6]. The influence of ghre lin on both endocrine and exocrine pancreatic function and glucose metabolism suggests that it would play a major role in the endocrine abnormalities commonly present in obesity[7].

Previous studies have provided contradictory findings on various single nucleotide poly morphis ms (SNPs) in Ghrelin as to their association with obesity and obesity-related phenotypes[8]. One common SNP detected is Arg51Gln (rs34911341), resulting from a single base substitution G152A, with Gln replacing Arg at codon 28 of mature ghrelin[9]. The Arg51Gln mutation results in a change in the $\mathrm{COOH}$-terminal processing site of the ghrelin peptide within its precursor protein from Proline-Arginine to Proline-Glutamine, resulting in the failure of the normal cleavage necessary to produce the 28-a mino acid ghrelin[10]. A 94-amino-acid long pro-ghrelin peptide may still be produced, although its biological activity has not been assessed[10]. Several association studies on the Arg51Gln SNP conducted in different populations mostly revealed negative associations - for example the Italian population [11] and the German populations[12,13], where the allele frequencies of the SNP were similar between non-obese and obese subjects. Also, according to the study of Pöykkö et al. (2003), the Arg51Gln variant was associated with T2DM and elevated blood pressure in the middle-aged Finnish subjects; however, was not associated obesity phenotypes [14]. Currently, there is limited data and evidence on this association among the Malaysian population. As different populations show different associations in the existing research, the data on the association of this Ghrelin SNP with obesity in other populations cannot be used to extrapolate for the Malaysian population. Therefore, the objective of this study was to perform genotyping of the Ghrelin Arg51Gln SNP among Malaysian subjects from a health clinic in Kampar, Perak to determine the prevalence of the mutated genotypes and alleles, and to investigate if there was any association with obesity. Demographic characteristics, anthropometric measurements, blood pressures and fasting plasma glucose level were also determined to investigate whether there is any association of these obesity and metabolic syndrome-re lated traits with the Ghrelin Arg51Gln SNP.

\section{Methodology}

\subsection{Study Participants, Questionnaire and Measurements}

A total of 184 unrelated subjects (age range: 21-80; overall mean age: $54.8 \pm 13.6$ - males: $57.88 \pm 15.2$, females: $53.2 \pm 12.3$ ) were recruited by convenience sampling from the Kampar Health Clinic from June to December, 2011, and their baseline characteristics are shown in Table 1. The exclusion criteria of the subjects include hyperthyroidism, pituitary diseases, chronic liver disease, chronic renal disease, acute infection, haematologic diseases and patients under medications that affect the glucose metabolis $\mathrm{m}$.

Table 1. Baseline characteristics of study participants

\begin{tabular}{|c|c|c|c|}
\hline Variable & $\begin{array}{c}\text { Male } \\
n=67\end{array}$ & $\begin{array}{l}\text { Female } \\
n=117\end{array}$ & $\begin{array}{c}\text { Total } \\
N=184\end{array}$ \\
\hline \multicolumn{4}{|c|}{ BMI status } \\
\hline Non-obese & 40 (59.7) & $68(58.1)$ & $108(58.7)$ \\
\hline Obese & $27(40.3)$ & 49 (41.9) & $76(41.3)$ \\
\hline \multicolumn{4}{|c|}{ Age } \\
\hline $21-30$ & 7 (10.4) & $8(6.8)$ & $15(8.2)$ \\
\hline $31-40$ & 1 (1.5) & $6(5.1)$ & 7 (3.8) \\
\hline $41-50$ & $8(11.9)$ & $33(28.2)$ & $41(22.3)$ \\
\hline $51-60$ & $19(28.4)$ & $39(33.3)$ & $58(31.5)$ \\
\hline $61-70$ & $21(31.3)$ & 23 (19.7) & 44 (23.9) \\
\hline $71-80$ & $11(16.4)$ & $8(6.8)$ & $19(10.3)$ \\
\hline \multicolumn{4}{|c|}{ Ethnicity } \\
\hline Malay & $16(23.9)$ & $36(30.8)$ & $52(28.3)$ \\
\hline Chinese & 42 (62.7) & 49 (41.9) & $91(49.4)$ \\
\hline Indian & $9(13.4)$ & $32(27.4)$ & $41(22.3)$ \\
\hline
\end{tabular}

Demographic data included in this questionnaire were age, gender and self-identified ethnicity; while blood pressures and anthropometric measurements consisting of systolic and diastolic blood pressures (SBP, DBP), pulse rate, weight, body mass index (BMI), waist and hip circu mferences, total body fat (TBF), subcutaneous fat (SF), visceral fat level (VFL) and skeletal muscle (SM) were taken as described in our previous study[15]. Subjects with the BMI cut-off point of $\geq 27.0 \mathrm{~kg} / \mathrm{m}^{2}$ were considered as obese[16].

Overnight fasting peripheral blood drawing was conducted with the aid of a qualified phlebotomist. Fasting plasma glucose level was determined by using OneTouch ${ }^{\circledR}$ Ultra Easy ${ }^{\mathrm{TM}}$ blood glucose meter and test strips (LifeScan Inc., CA). The presence of MetS was based on the only three accessible criteria out of five risk factors in accordance to the modified NCEP ATP III definition of metabolic syndrome for Asians: WC $>80 \mathrm{~cm}$ for women and $>90 \mathrm{~cm}$ in men, hyperglycaemic/having elevated fasting plasma glucose of > $6.1 \mathrm{mM}$ or currently being treated for diabetes and having blood pressure of $\geq 130 / 85 \mathrm{mmHg}$.

This study was registered under the National Medical 
Research Registry NMRR-09-826-4266 and the protocol was approved by the Medical Research and Ethics Committee, Ministry of Health, Malaysia. All individuals that have participated in this study signed informed consent forms and all samples were taken in accordance with the Declaration of Helsinki (revised in Seoul, 2008).

\subsection{DNA Extraction and Genotyping}

Five millilitres of blood sample was collected and genomic DNA was then extracted from the nucleated leukocytes using the Wizard ${ }^{\circledR}$ Genomic DNA Purification Kit (Promega Inc., Madison, WI) as mentioned in our previous study[15]. Each of the PCR reaction vial contained $20 \mu$ l of solution, containing forward primer $(2 \mathrm{mM})$, reverse primer $(2 \mathrm{mM})$, PCR buffer with $\mathrm{KCl}(1 \times)$, Taq DNA polymerase recombinant $(1 \mathrm{U} / \mu \mathrm{l})$ (Fermentas, Lithuania), dNTP (0.2 mM) (Axygen Biosciences Inc., CA ) and $\mathrm{MgCl}_{2}$ $(1.5 \mathrm{mM})$. The PCR was carried out using Biometra $\mathrm{T}$ Personal Thermocycler (Biometra GmbH, Germany), according to the conditions and primer sets used in a previous study[17]. The wild-type homozygous Arg51Arg refers to base G152G or known as the 'GG' genotype, heterozygous Arg51Gln refers to base G152A or ' $\mathrm{GA}$ ' genotype, while mutated homozygous Gln51Gln refers to base A152A or 'AA' genotype. The fragments were resolved by $3 \%$ agarose gel electrophoresis at constant $90 \mathrm{~V}$ for 45 min before staining with ethidiu m bro mide and vie wed under a UV transillu minator. The three genotypes were validated by sending to an outsourced DNA sequencing service.

\subsection{Statistical Analysis}

Statistical Package for Social Students, IBM ®SPSS ® Statistics for Window ${ }^{\circledR}$ Version 16.0 (SPSS Inc., IL) was used to analyze the data. The normality of data was examined using One-Sample Kolmogorov-Smirnov Test whereby $p>0.05$ indicates that the particular variable is normally distributed. Descriptive statistics was used to compute frequencies and percentages for demographic data, genotype and allele frequencies, and also to compute means and standard deviations for anthropometric measurements. Besides, Pearson's Chi-square analysis was used to compare the difference in the genotype and allele distributions between groups. Means of clinical parameters were compared by Student's $t$-test (between two variables) or using One-Way Analysis of Variance (ANOVA) (between more than two variables), except for VFL and fasting plasma glucose level whereby they were compared using Mann-Whitney $U$ test (between two variables) or Kruskal-Wallis test (between more than two variables). In all statistical tests performed, $p<0.05$ was denoted as statistically significant.

\section{Results}

The alle le frequency for the mutated $51 \mathrm{Gln}$ or A allele (or known as Minor Allele Frequency, MAF) was 0.196, where
48 or $63.2 \%$ of the obese subjects carried GG genotype, 28 or $36.8 \%$ had GA genotype, while none had the AA genotype. The only AA genotype was detected in a normoglycaemic non-obese but hypertensive (based on SBP and DBP) Chinese male subject, aged 73. As there was only one subject with the AA genotype, we categorised the demographic and clinical variables based on alleles (Table 2).

Table 2. GHS Arg51Gln genotype and allele frequencies with respect to BMI stat us, gender, ethnicity, glycaemia stat us, hypertensive stat us (based on SBP and DBP) and metabolic syndrome stat us

\begin{tabular}{|c|c|c|}
\hline \multirow[t]{2}{*}{ Variables } & \multicolumn{2}{|c|}{ Allele } \\
\hline & G & A \\
\hline \multicolumn{3}{|l|}{ BMI status } \\
\hline Obese & $124(81.6)$ & $28(18.4)$ \\
\hline Non-Obese & $172(79.6)$ & $44(20.4)$ \\
\hline$\chi^{2} ; p$ & \multicolumn{2}{|c|}{$0.215 ; 0.643$} \\
\hline \multicolumn{3}{|l|}{ Gender } \\
\hline Male & $101(75.4)$ & 33 (24.6) \\
\hline Female & $195(83.3)$ & $39(16.7)$ \\
\hline$\chi^{2} ; p$ & \multicolumn{2}{|c|}{$3.431 ; 0.064$} \\
\hline \multicolumn{3}{|l|}{ Ethnicity } \\
\hline Malay & $79(76.0)$ & $25(24.0)$ \\
\hline Chinese & $149(81.9)$ & $33(18.1)$ \\
\hline Indian & $68(82.9)$ & $14(17.1)$ \\
\hline$\chi^{2} ; p$ & \multicolumn{2}{|c|}{$1.884 ; 0.390$} \\
\hline \multicolumn{3}{|l|}{ Glycaemia status } \\
\hline Normal & $135(80.4)$ & $33(19.6)$ \\
\hline Hyperglycemic & $161(80.5)$ & $39(19.5)$ \\
\hline$\chi^{2} ; p$ & \multicolumn{2}{|c|}{$0.001 ; 0.973$} \\
\hline \multicolumn{3}{|l|}{ SBP category } \\
\hline Normal & $96(84.2)$ & $18(15.8)$ \\
\hline Hypertensive & $200(78.7)$ & $52(21.3)$ \\
\hline$\chi^{2} ; p$ & \multicolumn{2}{|c|}{$1.496 ; 0.221$} \\
\hline \multicolumn{3}{|l|}{ DBP cat egory } \\
\hline Normal & $182(82.0)$ & $40(18.0)$ \\
\hline Hypertensive & $114(78.1)$ & $32(21.9)$ \\
\hline$\chi^{2} ; \mathrm{p}$ & \multicolumn{2}{|c|}{$0.851 ; 0.356$} \\
\hline \multicolumn{3}{|l|}{ Metabolic syndrome } \\
\hline Absent & $204(80.3)$ & $50(19.7)$ \\
\hline Present & $92(80.7)$ & $22(19.3)$ \\
\hline$\chi^{2} ; \mathrm{p}$ & \multicolumn{2}{|c|}{$0.007 ; 0.931$} \\
\hline
\end{tabular}

Numbers in parenthesis are percentages out of the total cases for the variable in the same row. $\chi^{2}$ and $p$-values by Pearson's Chi-square analysis, significant at $p<0.05$

More females carried the $\mathrm{G}$ allele compared to males. Chinese had the highest GG genotypes among them, which led to them carrying the highest number of $\mathrm{G}$ alleles. There were more subjects with the Gallele who had hypertension based on SBP compared to normotension, but the opposite was true for categorisation of hypertension based on DBP. More than half of the overall subjects were with the $G$ allele and had no presence of metabolic syndrome. Based on Chi-square test, BMI status, gender and ethnicity did not show association with different Ghrelin A rg51Gln alleles. Besides, presence or absence of hyperglycaemia, hypertension (based on SBP or DBP) and metabolic 
syndrome were also all not associated with Ghrelin Arg51Gln alle les (Table 2). There were also no significant differences between anthropometric and clinical measurements between the two different alleles (Table 3), indicating that obesity- and metabolic syndrome-related phenotypes were all not associated with the Ghrelin Arg51Gln SNP.

Table 3. Mean and standard deviation of anthropometric and clinical measurements with respect to GHS Arg51Gln genotypes and alleles

\begin{tabular}{cccc}
\hline $\begin{array}{c}\text { Anthropometri } \\
\text { c and Clinical } \\
\text { Measurements }\end{array}$ & $\mathrm{G}$ & $\mathrm{A}$ & $p$ value \\
\hline SBP $(\mathrm{mmHg})$ & $140.6 \pm 22.1$ & $145.3 \pm 22.5$ & 0.930 \\
$\begin{array}{c}\text { DBP }(\mathrm{mmHg}) \\
\text { Pulse }\end{array}$ & $81.0 \pm 12.1$ & $83.3 \pm 12.2$ & 0.504 \\
$\begin{array}{c}\text { Rate }(\mathrm{bpm}) \\
\text { WC }(\mathrm{cm})\end{array}$ & $77.6 \pm 13.7$ & $77.8 \pm 11.9$ & 0.079 \\
WHR & $0.9 \pm 0.1$ & $0.9 \pm 0.1$ & 0.695 \\
Weight (kg) & $65.9 \pm 13.9$ & $67.3 \pm 13.5$ & 0.972 \\
BMI $\left(\mathrm{kg} / \mathrm{m}^{2}\right)$ & $26.8 \pm 5.4$ & $26.7 \pm 5.2$ & 0.766 \\
TBF $(\%)$ & $33.5 \pm 7.3$ & $32.8 \pm 7.5$ & 0.501 \\
SF $(\%)$ & $28.1 \pm 8.1$ & $26.8 \pm 9.0$ & 0.106 \\
VFL $(\%)^{\S}$ & $11.9 \pm 6.5$ & $12.2 \pm 6.0$ & 0.399 \\
RM (kcal) & $1382.4 \pm 234$ & $1422.6 \pm 216.3$ & 0.655 \\
SM $(\%)$ & $23.7 \pm 5.3$ & $24.4 \pm 6.2$ & 0.185 \\
$\begin{array}{c}\text { Fasting plasma } \\
\text { glucose level } \\
\text { (mmol) }^{\S}\end{array}$ & $7.3 \pm 3.2$ & $7.0 \pm 2.8$ & 0.118 \\
\hline
\end{tabular}

$p$-values by Student's $t$ test or One-way ANOVA for normally-distributed data or Kruskal-Wallis and Mann-Whitney $U$ test for non-normally distributed data ${ }^{\S}$; significant at $p<0.05$

\section{Discussion}

The present study has demonstrated the existence of SNPs in the Ghrelin gene. One of the SNP reported in other studies [9,11,12-14], i.e. Arg51Gln, was also found in our study population, although without any association with obesity and metabolic syndrome. In our multi-ethnic subjects, the frequency for the $51 \mathrm{Gln}$ allele of 0.196 was much higher than the Swedish (0.031)[9], Italian (0.006)[11], German (0.016)[12] and Finnish (0.022)[14] Caucasian populations and Old Order Amish population (0.030)[18]. This rare Ghrelin Arg51Gln SNP was not even detected in two Chinese cohorts studied[17,19]. The Swedish study found association of this SNP with obesity[9], whereas the latter populations mentioned above did not. All these probably reflect genetic or ethnic heterogeneity between populations; therefore the data on the association of the Ghrelin Arg51Gln SNP with obesity in other populations cannot be used to extrapolate for the Malaysian population.

Subjects with higher BMI tend to have low ghrelin concentration[20]. A previous study has found that the subjects of $51 \mathrm{Gln}$ allele had lower ghrelin concentrations [17]. This is due to the amino acid sequence of the mature peptide was modified by Arg51Gln, subsequently; the production of ghrelin level was reduced[17]. 51Gln carriers also had lower concentrations of insulin-like growth factor-1 (IGF-I) and higher concentrations of insulin-like growth factor binding protein 1 (IGFBP-1) compared to the non-carriers[21]. The reduced level of ghre lin concentrations were independently associated with several co mplications such as type 2 diabetes, insulin concentration, and insulin resistance and others[21]. Therefore, the Arg51Gln SNP has also been associated with components of metabolic syndrome, such as hyperglycaemia/type 2 diabetes and hypertension. According to the study of Xie et al. (2008), hyperglycaemia was found to be associated with the Arg51Gln SNP[22]. Other studies such as Pöykkö et al. (2008) and Krzy zanowska-Swin iarska et al. (2005) also reported that $51 \mathrm{Gln}$ allele carriers had higher prevalence of hypertension[21,23]. Therefore, the allele $51 \mathrm{Gln}$ was known a risk factor to hypertension, as low ghrelin level was found to be inversely as sociated to SBP and DBP [21,23]. However, there was absence of association of Ghre lin Arg51Gln SNP with hyperglycaemia, hypertension and metabolic syndrome in our study, again indicating genetic/ethnic heterogeneity between different populations.

This study had some limitations whereby the respondents may not represent the whole Kampar population as only 184 subjects were studied. In addition, small sample size leads to the inconsistency of the results therefore limiting the power for statistical analysis and extrapolation. In future, the sample size of subjects should be increased. Younger adults will be more preferable as study subjects as the majority of the subjects that fell in the older age group of 51 to 60 in the current study may confound the results. In addition, lipid profiles such as triglyceride concentration and high-density lipoprotein cholesterol level could be included as well to expand the criteria for the diagnosis of metabolic syndrome. It will be interesting also to study the gene-environment interaction involved in obesity and metabolic syndrome, as dietary habits (such as high fat and high cholesterol diet) and lifestyle factors (such as physical activity) may affect Ghrelin gene activation and responses.

\section{Conclusions}

In our study, we confirmed and replicated the findings of the German, Italian, Finnish, Old Order Amish and Chinese population studies for the non-association of Ghrelin Arg51Gln SNP with obesity, obesity-related traits and metabolic syndrome in this multi-ethnic Malaysian study group. The distribution of the genotype and allele frequencies of this gene variant was also not significantly different among gender and ethnic groups. On the basis of the results available so far, the role of the coding missense substitution Arg51Gln gene variant of Ghrelin in obesity, metabolic syndrome and their related traits remains inconclusive.

\section{ACKNOWLEDGEMENTS}


This project was funded by the Universiti Tunku Abdul Rah man Research Fund (IPSR/RMC/UTARRF/C111/C35). We would like to extend our deepest gratitude to the Kampar District Health Office for g ranting us permission to carry out this study at the Kampar Health Clinic, the nurses who assisted with the blood sampling, and all the respondents who have volunteered to participate in this study.

\section{REFERENCES}

[1] Online available:http://www.who.int/mediacentre/factsheets /fs311/en/ind ex.html

[2] S. Suzana, C.C. Kee, A.R. Jamaludin, M.N. Noor Safiza, G.L. Khor, H. Jamaiy ah, A. Geeta, Z. Ahmad Ali, R. Rahmah, A.T. Ruzita, Y. Ahmad Fauzi, The Third National Health and Morbidity Survey: prevalence of obesity, and abdominal obesity among the Malaysian elderly population, SAGE Publications, Asia Pac. J. Public Health, vol. 24, pp. 318-329, 2012.

[3] E. Kassi, P. Pervanidou, G. Kaltsas, G. Chrousos, Metabolic syndrome: definitions and controversies, BioMed Central, BMC Med., vol. 9, pp. 48, 2011.

[4] A. J. Lely, M. Tschop, M. L. Heiman, E. Ghigo, Biological, physiological, pathophysiological, and pharmacological aspects of ghrelin, The Endocrine Society, Endocr. Rev., vol. 25, pp. 426-457, 2004.

[5] M.P. Wajnrajch, I.S. Ten, J.M. Gertner, R.L. Leibel, Genomic organization of human ghrelin gene, BMJ Publishing Group, J. Med. Genet., vol. 1, pp. 231-233, 2000.

[6] T. R. Castañeda, J. Tong, R. Datta, M. Culler, M. H. Tschöp, Ghrelin in the regulation of body weight and metabolism, Elsevier, Front. Neuroendocrin., vol. 31, pp. 44-60, 2010.

[7] O. Ukkola, Ghrelin and metabolic disorders, Bentham Science, Curr. Protein Pept. Sci., vol. 10, pp. 2-7, 2009.

[8] O. Ukkola, E. Ravussin, P. Jacobson, L. Perusse, T. Rankien, M. Tshöp, M.L. Heiman, A.S. Leon, D.C. Rao, J.S. Skinner, J.H. Wilmore, L. Sjostrom, C. Bouchard. Role of ghrelin polymorphisms in obesity based on three different studies, Nature Publishing Group, Obes. Res., vol. 10, pp. 782-791, 2002.

[9] O. Ukkola, E. Ravvussin, P. Jacobson, E. E. Snyder, M. Changnon, L. Sjostrom, C. Bouchard, Mutations in preproghrelin/ghrelin gene associated with obesity in humans, The Endocrine Society (USA), J. Clin. Endocrinol. Metab., vol. 8, pp.3996-3999, 2001.

[10] M. Kojima, K. Kangawa, Ghrelin: Structure and function, American Physiological Society, Physiol_. Rev., vol. 85, pp. 495-522, 2005.

[11] D. Vivenza, A. Rapa, N. Castellino, S. Bellone, A. Petri, G. Vacca, G. Aimaretti, F. Broglio, G. Bona, Ghrelin gene polymoophism and ghrelin, insulin, IGF-1, leptin and anthropometric data in children and adolescents.
BioScientifica, Eur. J. Endocrinol., vol. 151, pp. 127-133, 2004.

[12] A. Hinney, A. Hoch, F. Geller, H. Schafer, W. Siegfried, H. Goldschmidt, H. Remschmidt, J. Hebebrand, Ghrelin Gene: Identification of missense variants and a frameshift mutation in extremely obese children and adolescents and healthy normal weight students. The Endocrine Society (USA), J. Clin. Endocrinol. Metab., vol. 87, pp. 2716-2719, 2002.

[13] L.H. Larsen, A. P. Gjesing, T. I.A. Sorensen, Y. H. Hamid, S. M. Echwald, S. Toubro, E. Black, A. Astrup, T. Hansen, O. Pedersen, Mutation analysis of the preproghrelin gene: No association with obesity and type 2 diabetes. Elsevier, Clin. Biochem., vol. 38, pp. 420-424, 2005.

[14] S. Pöykkö, O. Ukkola, H. Kauma, M. J. Savolainen, Y. A. Kesäniemi, Ghrelin Arg51Gln mutation is a risk for type 2 diabetes and hypertension in a random sample of middle-aged subjects. Springer, Diabetologia, vol. 46, pp. 455-458, 2003.

[15] P.M. Chan, S.H. Fan, Y.H. Say, No association of Peptide Tyrosine-Ty rosine (PYY) gene R72T variant with obesity in the Kampar Health Clinic Cohort, Malaysia, Nutrition Society of Malaysia, Mal. J. Nutr., vol. 17,pp. 201-202, 2011.

[16] M. Deurenberg-Yap, G. Schmidt, W.A. Van Staveren, P. Deurenberg, The paradox of low body mass index and high body fat percentage among Chinese, Malays and Indians in Sin gapore. Nature Publishing Group, Int. J. Obes., vol. 24, pp. 1011-1017, 2000.

[17] K. Wang, L. Wang, Y. Zhao, Y. Shi, L. Wang, Z. Chen, No Association of the Arg51Gln and Leu72M et poly morphism of the ghrelin gene and polycyctic ovary syndrome. Oxford Journals, Hum. Reprod., vol. 24, pp. 485-490, 2009.

[18] N.I. Steinle, T.I. Pollin, J.R. O'Connell, B.D. Mitchell, A.R. Shuldiner, Variants in the ghrelin gene are associated with metabolic syndrome in the Old Order Amish. The Endocrine Society (USA), J. Clin. Endocrinol. Metab., vol. 90, pp. 6672-6677, 2005.

[19] J.F. Zhu, L. Liang, C.C. Zou, J. F. Fu, Plasma ghrelin levels and polymorphism of ghrelin gene in Chinese obese children and adolescents, Springer, Ir. J. Med. Sci., vol. 179, pp. 345-349, 2010.

[20] L. Pulkkinen, O. Ukkola, M. Kolehmainen, M. Uusitupa, Ghrelin in diabetes and metabolic syndrome, Hindawi, Int. J. Pept., vol. 2010, pp. pii: 248948, 2010.

[21] S. Pöykkö, E. Kellokoski, S. Horkko, H. Kauma, Y. A. Kesaniemi, O. Ukkola, Low plasma ghrelin is associated with insulin resistance, hypertension, and the prevalence of type 2 diabetes, American Diabetes Association, Diabetes, vol. 52, pp. 2546-2553, 2008.

[22] X. Xie, J. Zhang, Y. Wang, C. Zhang, J. Wang, X. Yuan, H. $\mathrm{Ni}$, Ghrelin gene polymorphism and Xi'an Han Arg51Gln type 2 diabetes, hypertension associated, Chinese Electronic Periodical Services, J. Xi'an Jiaotong Univ. (Med. Sci.) vol. 1, pp. 80-83, 2008.

[23] B. Krzyzanowska-Swiniarska, A. Kempa, M. Robaczyk. Preproghrelin gene, ghrelin receptor and metabolic syndrome. Przeglad Lekarski, Przegl. Lek., vol. 62, pp. 230-233, 2005. 